\title{
Financial contagion and depositor monitoring
}

\author{
Augusto Hasman ${ }^{\mathrm{a}, \mathrm{b}, *}$, Margarita Samartín ${ }^{\mathrm{c}}$, Jos Van Bommel ${ }^{\mathrm{d}}$ \\ ${ }^{a}$ Graduate Institute of International and Development Studies, Switzerland \\ ${ }^{\mathrm{b}}$ OFCE, Sciences-Po, Paris, France \\ ${ }^{\mathrm{c}}$ Business Department, Universidad Carlos III de Madrid, Spain \\ d Luxembourg School of Finance, University of Luxembourg, Luxembourg
}

\section{A R T I C L E I N F O}

\section{Article history:}

Received 26 January 2012

Accepted 26 February 2013

Available online 23 March 2013

\section{JEL classification:}

G21

D82

Keywords:

Bank runs

Capital requirements

Contagion

Deposit insurance

Information

Market discipline

\begin{abstract}
A B S T R A C T
This paper analyzes market discipline in a many-bank economy where contagion and bank runs interact. We present a model with differently-informed depositors, where those depositors that are more informed have incentives to monitor banks' investments. It is shown that when banks are undercapitalized, and the probability of success of the risky asset is low, depositors might prefer a contract that is subject to bank runs in the interim period to a contract that allows banks to gamble with their funds and maintain their investment.The results of the paper emphasize the benefits of private monitoring of banks in order to promote market discipline.
\end{abstract}

(c) 2013 Elsevier B.V. All rights reserved.

\section{Introduction}

The recent financial turmoil has restored the debate concerning deposit insurance schemes. European governments have increased depositors' protection up to almost $100 \%$, in an attempt to prevent panic bank runs. Nevertheless, this policy was implemented before knowing the real quality of banks' assets. It is largely claimed that these interventions will intensify the riskiness of banks' investments and generate bankruptcies and contagion in the future. All these events have called for a system of supervision that prevents institutions from taking on excessive risk. Additionally, they have highlighted that a sound transparency framework based on improved disclosure and high quality accounting standards is essential in order to ensure market confidence and enhance market discipline.

Market discipline is one of the three pillars generally accepted by regulators and scholars to limit the bank risk-shifting incentives that are exacerbated by financial safety nets. Nevertheless, the incentives to acquire information and exercise market discipline vary across countries and depend on the regulatory, institutional

\footnotetext{
* Corresponding author. Address: Pavillon Rigot, Avenue de la Paix 11A, 1202 Geneva, Switzerland. Tel.: +41 33628489427.

E-mail addresses: augusto.hasman@graduateinstitute.ch (A. Hasman), samartin@ emp.uc3m.es (M. Samartín), jos.vanbommel@uni.lu (J.V. Bommel).
}

and supervisory environment (see Fonseca and González, 2010; Cubillas et al., 2012).

There is empirical research that has documented that depositors exercise market discipline in banking, even in the presence of deposit insurance. Martinez Peria and Schmukler (2001) study the experiences of Argentina, Chile, and Mexico during the 1980s and 1990s. They find that depositors punish banks for risky behavior, by both withdrawing their deposits and requiring higher interest rates. ${ }^{1}$ Market discipline becomes more important after crises and deposit insurance does not appear to diminish the extent of market discipline. Similar results are found by Hosono et al. (2005) for the case of Asia. Hadad et al. (2011) analyze changes in the deposit-guarantee scheme and capital regulation in Indonesian banks following the 1997-1998 financial crisis. They find that the adoption of a blanket-guarantee scheme weakens market discipline, although market discipline works better in listed banks than unlisted banks and in foreign banks than domestic ones.

Additionally, recent papers have shown that market discipline varies with the particular regulatory, supervisory, and institutional environment. For example, Demirgüç-Kunt and Huizinga (2004) analyze whether differences in market discipline across countries can be explained by different designed features of financial safety

\footnotetext{
${ }^{1}$ For example, bank deposits in Greece have fallen by 70 billion euros since the start of the crisis in 2009.
} 
nets. In particular, they show that co-insurance, coverage of foreign currency deposits, and private and joint management of insurance schemes may improve market discipline. Cubillas et al. (2012) have also analyzed to what extent variations in market discipline after a banking crisis depend on a country's bank regulation, supervision, and institutions. They provide evidence that the adoption of an explicit blanket guarantee, forbearance, government recapitalization, and nationalization programs are interventions that have a weakening effect on market discipline.

The aim of this paper is to analyze market discipline and its effect on financial contagion. This is a very important topic as it is precisely during crises when governments tend to adopt blanket guarantees to avoid runs (in fear of a systemic crisis) and thus these policies weaken market discipline and increase bank risk taking in the future. Our results suggest that, in certain circumstances, allowing for runs (and hence contagion) might be welfare superior to maintaining risky banks operating. To the best of our knowledge, this is the first paper that analyzes market discipline in a many bank economy where bank runs and contagion interact.

We model a two region economy, with a continuum of riskaverse consumers (depositors) and risk-neutral investors (bankers). Consumers have the standard Diamond-Dybvig preferences. Banks in each region have access to illiquid long-term investment projects, that allow depositors to increase their expected welfare. In particular, at $t=0$, banks can choose between a safe asset and a risky one (the gambling asset) that yields a lower expected return at $t=2$. However, this gambling asset may become attractive when banks are undercapitalized. At $t=1$, some depositors acquire information about the bank's investments. In particular, these depositors may run on the bank, if the bank has invested in the gambling asset. On the other hand, banks are fully rational and are aware that depositors can obtain information. Hence, in order to avoid a bank run in the interim period, the bank contract has to be appropriately designed. We will refer to this contract as the run-proof contract. We show that when banks are undercapitalized (and hence, have incentives to take risk), depositors might prefer a contract that is subject to bank runs in the interim period to a contract that prevents runs and allow banks to gamble and maintain their investment (run-proof contract), provided that the probability of success of the gambling asset is low. ${ }^{2}$ Finally, it is assumed that the two regions have negatively correlated liquidity shocks, and so banks will maintain interbank linkages in order to ensure themselves against the liquidity shock. As a result, during a crisis, the failure of one institution may have negative effects on the other institution to which it is linked (contagion).

In particular, we build on the model by Brusco and Castiglionesi (2007), from now on BC, but we modify their framework by introducing the possibility of differently informed depositors. BC analyzed the propagation of financial crises among regions affected by moral hazard problems. In their paper, the existence of limited liability and insufficiently capitalized banks promoted excessive risk taking by banks. This lead to a situation where bankruptcy (and contagion) occurred with positive probability at $t=2$. In fact, for certain parameter values, depositors preferred a contract that allowed banks to gamble with their money to one that restricted banks to be sufficiently capitalized, in order to avoid the moral hazard problem. However, in the BC model there is no possibility for depositors to acquire information. Therefore, in case there would be such possibility, their implicit assumption is the presence of full deposit insurance.

We depart from BC by considering the possibility of acquiring information. In our model a fraction of uninsured depositors

\footnotetext{
2 Alonso (1996) and Samartín (2003) find similar results but in a single-bank economy where contagion effects cannot be considered.
}

receive information about the bank's investment and may run on the bank. However, runs are not necessarily bad from an ex-ante point of view. Depositors will only allow banks to gamble with their money and maintain their investment, when the probability of success of the gambling asset is sufficiently high (the asset is not very risky). Our results come from the fact that the run-proof contract reduces the consumption of impatient agents, even in the presence of the gambling asset. Then, for low probabilities of success of the gambling asset, the allocation that allows for runs and makes consumption indirectly contingent on the information shock, is preferred. The benefits of private monitoring of banks have been emphasized by the empirical literature. For example, Barth et al. (2004) find, in an extensive study that examines various bank regulations and supervisory practices in 107 countries, that regulations that encourage private monitoring of banks are associated with better banking sector outcomes, greater bank development, lower net-interest margins and small non-performing loans. However, they also show that private monitoring does not reduce the likelihood of a banking crisis. ${ }^{3}$

Market discipline has also been analyzed by several papers in the theoretical banking literature, but in a single-bank economy (where the interaction between bank runs and contagion is not analyzed). The idea of these papers is that uninsured and liquid deposits keep the bank's portfolio choice in line with depositors' preferences. The threat of a bank run by informed depositors after receiving negative information discourages banks' owners from investing in projects that are too risky or committing fraud (see Calomiris and Kahn, 1991; Flannery, 1994; Jean-Baptiste, 1999 or Gorton and Huang, 2003. Dwyer and Samartín, 2009 contains a review of this literature). ${ }^{4}$ In our paper, market discipline is exercised by depositors that withdraw their deposits in order to punish banks for bad behavior. On the other hand, we follow one strand of the contagion literature that motivates the existence of contagion through the interbank market. A common feature of this literature is that banks have incentives to establish links ex ante, in order to protect themselves against liquidity shocks, but during a crisis, the failure of one institution may have negative effects on other institutions to which it is linked (see Allen and Gale, 2000; Brusco and Castiglionesi, 2007; Castiglionesi, 2007; Hasman and Samartín, 2008). ${ }^{5}$

The rest of the paper is organized as follows: the basic model is presented in Section 2. Section 3 describes the socially-optimal allocation. Section 4 analyzes the decentralized solution under different scenarios and Section 5 provides some welfare comparisons using numerical simulations. Finally, the concluding remarks are summarized in Section 6.

\section{The model}

The model builds on Brusco and Castiglionesi (2007). There a three dates $(t=0,1,2)$ and a single good. There are two regions, $A$ and $B$. Each region has a continuum of depositors and a banking sector. Depositors are ex-ante identical and are endowed with one unit of the good at $t=0$. At $t=1$, individuals can be of type- 1 (or impatient) with probability $w^{s}$ and derive utility from consumption only in that period, or they can be of type-2 (or patient)

\footnotetext{
${ }^{3}$ Bhattacharya et al. (1998) and Chen and Hasan (2006) also provide a discussion of the optimality of partial deposit insurance and empirical evidence that supports it.

${ }^{4} \mathrm{Qi}$ (1998) and Diamond and Rajan (2001a,b, 2005, 2006), also study the disciplinary effects of liquid deposits in models that abstract from asymmetric information.

${ }^{5}$ Regarding the empirical literature on financial contagion, most of these papers find that contagion is possible but unlikely, that the size of the failing bank as well as the direction and type of linkages are key factors in determining the probability of contagion. One limitation of most of theses studies is that due to the lack of information on bank's mutual exposure, they have to assume a given distribution of interbank linkages. See Allen and Babus (2008), or European Central Bank (2010).
} 
with probability $1-w^{s}$ and derive utility from consumption only at $t=2$. The probability $w^{s}$ is also the fraction of impatient consumers in the population of region $i(i=A, B)$, and $w^{s}$ can take two values $w^{H}$ and $w^{L}$, with $w^{H}>w^{L}$ and equal probabilities. The average fraction of impatient consumers is $\gamma=\frac{w^{H}+w^{L}}{2}$.

The depositor's utility function is as follows:

$U\left(c_{1}, c_{2}\right)= \begin{cases}u\left(c_{1}\right) \text { with probability } w^{s} & \text { (Type }-1) \\ u\left(c_{2}\right) \text { with probability }\left(1-w^{s}\right) & (\text { Type }-2)\end{cases}$

Where the utility function $u($.$) is defined over non-negative levels of$ consumption, is strictly increasing, strictly concave, twice continuously differentiable, and satisfies Inada conditions. Consumer's type is his private information. The regions have perfect negative correlated liquidity shocks.

Finally, we consider risk-neutral investors (or bankers) endowed with $e$ units of the consumption good at $t=0$. These investors can either consume $\left(d_{o}\right)$ or buy shares from the banks, in such case they receive dividends $\tilde{d}_{t}$ at $t=1,2$. Their utility function is as follows:

$U\left(d_{0}, \tilde{d}_{1}, \tilde{d}_{2}\right)=R d_{o}+\tilde{d}_{1}+\tilde{d}_{2}$

Note that since investors obtain a utility of $R e$ by immediate consumption, they have to be rewarded at least $R$ for each unit of consumption they give up today. The incentive constraint is then: $d_{1}+d_{2} \geqslant R e$.

The banking sector in each region has access to long-term investment opportunities, and so individuals will deposit their endowment in the banking sector, in order to exploit those opportunities. Also, as liquidity shocks are negatively correlated across regions, banks are interested in maintaining interbank deposits to protect themselves against the liquidity shock. ${ }^{6}$

There are three types of assets or opportunities available to the bank in each region: the first one takes one unit of the consumption good at $t$ and transforms it into one unit at $t+1$ (storage or short asset), the second one is a long-term but safe asset that takes one unit at $t=0$ and transforms it into $R$ units at $t=2$ with certainty. Finally, there is a second long-term asset, the gambling asset, that transforms one unit at $t=0$ into $R$ units with probability $\eta$ and 0 with probability $(1-\eta)$, at $t=2$. Both of the long-term technologies cannot be liquidated prematurely at $t=1$, or equivalently, their liquidation value is close to zero. In order to introduce the moral hazard problem, it is assumed that the gambling asset produces an unobservable return $(\lambda-1) R$, for each unit invested at $t=0$, with $\lambda>1$ and $p \lambda<1$. Additionally, due to the limited liability assumption, depositors receive zero when the gambling asset does not succeed. Finally, it is also assumed that the opportunity of investing in the gambling asset appears with probability $p$ and is not verifiable. ${ }^{7}$

To complete the argument, we will consider that a proportion $\alpha$ (where $0 \leqslant \alpha \leqslant 1$ ) of type- 2 depositors become informed and they can observe whether the opportunity to invest in the gambling asset appears in their own bank but not in the bank in the other region. ${ }^{8}$

\footnotetext{
${ }^{6}$ For a motivation and description of the interbank market, see Allen and Gale (2000).

${ }^{7}$ As in Brusco and Castiglionesi (2007), the moral hazard problem cannot be solved through contracts, since outside parties cannot observe the investment choice of the bank or the extra return that it produces.

8 We can think that these informed depositors represent large uninsured depositors, that are not completely covered by the insurance fund, as well as other type of credit holders in countries where the institutional and regulatory environment enhance market discipline. On the other hand, it is true that there can be coordination problems among debt holders. That is why we assume a sequential service constraint. As Calomiris and Khan (1991) show the first come first served basis avoids that depositors free ride on each other, as they always have an incentive to be first in line to get paid. Note also, that when $\alpha \rightarrow 0$ we are in BC framework.
}

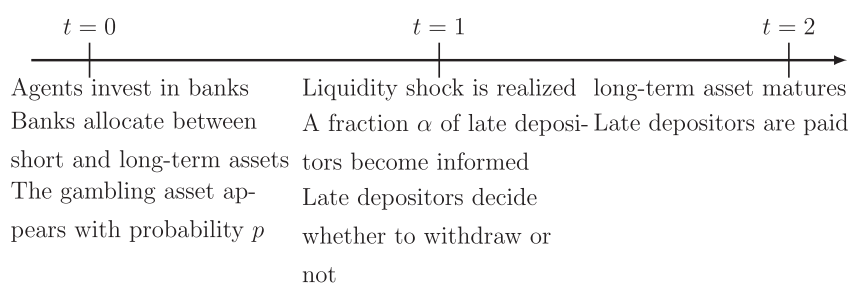

Fig. 1. Sequence of events.

This assumption is motivated by the fact that if information were costly, type- 2 depositors would be more likely to acquire information. Furthermore, if depositors were partially insured, large depositors would also be more likely to acquire the costly signal. These unmodeled aspects are taken into account by assuming that a fraction of type-2 depositors becomes informed. See Jacklin and Bhattacharya (1988) for a motivation of this assumption.

Finally, the sequence of events is as follows: at $t=0$, agents invest their endowment in banks. Banks then distribute this amount between the short and the long-term investments. Next, the opportunity to invest in the gambling asset appears with probability $p$. At $t=1$, agents decide whether to withdraw their money from banks (given the liquidity and information shocks). At $t=2$, the long-term project matures and patient depositors are paid. Fig. 1 illustrates the timing of the model.

\section{The social planner problem}

As a useful benchmark, we will first analyze the first-best allocation. Since consumers are ex-ante identical, it is natural to treat consumers symmetrically. We can therefore focus on the representative consumer in each region. Additionally, as there is no aggregate uncertainty, the optimal consumption will be independent of the state.

Clearly, in the Pareto optimal allocation there will be no gambling. Hence, the amount of capital owned by the risk-neutral investors is indeterminate. However, in the following sections, it is shown that the amount of capital does play a role in the decentralized economy.

The problem to be solved by a social planner is the following one:

$$
\begin{aligned}
& \underset{\left\{x, y, c_{1}, c_{2}\right\}}{\operatorname{Max}} \gamma u\left(c_{1}\right)+(1-\gamma) u\left(c_{2}\right) \\
& \text { s.t. } \\
& x+y \leqslant 1 \\
& \gamma c_{1} \leqslant y \\
& (1-\gamma) c_{2} \leqslant R x \\
& x, y, c_{1}, c_{2} \geqslant 0
\end{aligned}
$$

where $y$ is the amount invested in the short-term asset (storage), $x$ are resources invested in the long-term safe technology, $c_{1}$ is the consumption offered to an impatient consumer and $c_{2}$ is the consumption of a patient one.

Eq. (3) is the expected utility to be maximized. Eq. (4) is the budget constraint at $t=0$, that states that all resources should be used in storage or investment. Eq. (5) is the first-period constraint, which says that all the resources from storage should be used to pay the impatient depositor. Eq. (6) is the second-period constraint, where resources invested in the long-term technology are used to pay the patient depositor. Liquid funds might be rolled over from the first period but since the long-term technology is certain and strictly positive, rollover is ruled out.

Optimality requires that the feasibility constraints are satisfied with equality, so we can write the problem as 
$\operatorname{Max}_{y \in[0,1]} \gamma u\left(\frac{y}{\gamma}\right)+(1-\gamma) u\left(\frac{1-y}{1-\gamma} R\right)$

Since $u($.$) is strictly concave and satisfies the Inada conditions, the$ solution to problem (8) is unique and interior. The optimal value $y^{*} \epsilon(0,1)$ is obtained from the first-order condition

$u^{\prime}\left(\frac{y^{*}}{\gamma}\right)=R u^{\prime}\left(\frac{1-y^{*}}{1-\gamma} R\right)$

and once $y^{*}$ has been determined by Eq. (9) we can use the feasibility constraints to determine the other variables:

$c_{1}^{*}=\frac{y^{*}}{\gamma}, \quad c_{2}^{*}=\frac{\left(1-y^{*}\right)}{1-\gamma} R, \quad x^{*}=1-y^{*}$

Notice that (9) and (10) imply that $u^{\prime}\left(c_{1}^{*}\right)=R u^{\prime}\left(c_{2}^{*}\right)$, which in turn implies $u^{\prime}\left(c_{1}^{*}\right)>u^{\prime}\left(c_{2}^{*}\right)$ and $c_{2}^{*}>c_{1}^{*}$. Thus, the first-best allocation automatically satisfies the incentive constraint $c_{2} \geqslant c_{1}$, that is the late consumer has no incentive to behave as the early one. We will call $\Psi^{*} \equiv\left(y^{*}, x^{*}, c_{1}^{*}, c_{2}^{*}\right)$ the first-best allocation, and $U^{*}$ the expected utility achieved under the first-best allocation.

\section{Decentralized economy}

\subsection{No moral hazard}

When banks are sufficiently capitalized, there is no gambling, or equivalently, moral hazard is restrained and the first-best allocation can be attained by a decentralized economy, where the banks in both regions exchange interbank deposits at $t=0 .{ }^{9}$

Formally, we can state the following result:

Proposition 1 Brusco and Castiglionesi, 2007. The bank will invest in the long-safe asset only if the bank's capital is sufficiently large. When there is no moral hazard problem, the first-best allocation can be implemented by a decentralized banking system offering demand deposits.

The intuition is that when the amount of capital is large, bankers are more reluctant to gamble with their own money, and so they will invest in the safe asset.

The first-best allocation can be achieved as follows: at $t=0$, banks exchange interbank deposits for an amount $\left(w^{H}-\gamma\right)$ and offer the first-best contract $\left(c_{1}^{*}, c_{2}^{*}, x^{*}, y^{*}\right)$ to their depositors and to the bank in the other region (interbank deposits pay as the rest of deposits). At $t=1$, when a bank turns out to have the high-liquidity shock it liquidates interbank deposits held in the other bank. In the second year, interbank deposits move in the opposite direction, and so the low-liquidity bank receives deposits from the high-liquidity bank. In this way, by shifting deposits across regions, banks are able to satisfy the budget constraints, given by Eqs. (4)-(6), and provide depositors with the first-best allocation.

\subsection{Moral hazard with no information}

As we are interested in analyzing the effect of information and depositor monitoring on financial contagion, we assume for the rest of the paper that the exogenous amount of capital is scarce and so banks in both regions have incentives to invest in the gambling asset. ${ }^{10}$ Also, banks will exchange interbank deposits at $t=0$, for an amount $k$, in order to protect themselves against the liquidity shock. At $t=1$, the high-liquidity bank retrieves deposits from the low-liquidity bank in the other region. At $t=2$, deposits move in

\footnotetext{
9 The problem of decentralized economies in autarky is not solved in this paper, as we are interested in the effect of moral hazard issues and information in the propagation of crises among regions. For a description of that problem see BC.

10 The formal condition for banks to gamble is derived in BC.
}

the opposite direction, and so the low-liquidity bank pays back its deposits to the high-liquidity bank. It is assumed that banks can offer contracts contingent on the liquidity shock, although not on the appearance of the gambling asset. We then define by $c_{t}^{s}$ the consumption offered to a type- $t$ consumer (with $t=1,2$ ) in state $s$ (with $s=L, H$ ). We also assume that interbank deposits pay the same as the rest of deposits. For example, at $t=1$, the high-liquidity bank will retrieve $k c_{1}^{L}$ from the low-liquidity bank. At $t=2$, the high-liquidity bank will pay $k c_{2}^{H}$ to the low-liquidity one.

Note that consumption in the second period, will depend on the probability of bank failure in each region. For each region, let $q=(1-p)+\eta p$ be the probability that the gambling asset does not appear or that it appears and succeeds; while $(1-q)=p(1-\eta)$ is the probability that the gambling asset appears and fails. When the region experiences a high-liquidity shock, second-period consumption is just affected by what happens in that region. In this case, depositors receive the promised consumption $c_{2}^{H}$, with probability $q$ and $c_{2}^{A}$, which comes from funds available from storage (if any), when the gambling asset appears and fails, with probability $1-q$. If the region is affected by a low-liquidity shock, consumption in the second period is affected by what happens in both regions. We define by $c_{2}^{c}$ the consumption of a patient depositor in the low-liquidity region when its long-term investment is successful and the bank in the other region (say B) fails. In this case, bank A cannot retrieve completely the interbank deposit, and so there is contagion from region $B$ to region $A$. This happens with probability $q(1-q), c_{2}^{F}$ is the consumption of a patient depositor in the lowliquidity region when its own investment fails, but that of the other region does not. In this case, the available funds to pay depositors are those obtained from the interbank market and from storage (if any). This also happens with probability $(1-q) q$. When both regions' investments fail, which happens with probability $(1-q)^{2}$, then there is a meltdown of the entire financial system, and depositors receive $c_{2}^{B}$ (which is zero, if there is no storage from $t=1$ to $t=2$ ). Finally, when both investments are successful depositors receive the promised payment $c_{2}^{L}$. This happens with probability $q^{2}$.

Let us call $\Psi_{M H}=\left(c_{t}^{s}, c_{2}^{A}, c_{2}^{c}, c_{2}^{F}, c_{2}^{B}, x, y, k, d_{t}^{s}\right)$ the allocation when moral hazard is present, and $U_{M H}$ the expected utility achieved with moral hazard and no information.

The complete characterization of the optimal problem is provided in Appendix A. This is the original problem solved in BC.

The following result is obtained.

Proposition 2. If $p \rightarrow 0$, the expected utility achieved under moral hazard $\left(U_{M H}\right)$ tends to the first-best optimum $\left(U^{*}\right)$. Therefore, for a sufficiently low $p$ a contract that allows for gambling will be preferred to one that prevents moral hazard by restricting banks to be sufficiently capitalized.

\section{Proof. See Brusco and Castiglionesi (2007).}

The intuition is that the contract where moral hazard is prevented, does not reach the first best, as it restricts the amount of the long-term investment, with respect to the optimal one. Recall that as the exogenous amount of capital is scarce, the only way to increase capital is by increasing reserves and hence the amount invested in the long-term asset is decreased. Additionally, in this latter case the value of the expected utility does not depend on $p$. Therefore, for a sufficiently low $p$ gambling is preferred.

\subsection{Moral hazard with information: bank runs}

The discussion of the previous section ignored the fact that agents could acquire information about the bank's investment. In 
particular, we assume that banks offer the contract described by $\Psi_{M H}$. At $t=1$, a fraction of late depositors receives information about whether the opportunity to invest in the gambling asset appears in their own bank. These informed depositors will run on the bank whenever the expected utility of waiting is lower than the expected utility of withdrawing their deposits from the bank.

Formally, the incentive compatibility constraints are as follows:

$\eta\left[q u\left(c_{2}^{L}\right)+(1-q) u\left(c_{2}^{c}\right)\right]+(1-\eta)\left[q u\left(c_{2}^{F}\right)+(1-q) u\left(c_{2}^{B}\right)\right] \geqslant u\left(c_{1}^{L}\right)$

$\eta u\left(c_{2}^{H}\right)+(1-\eta) u\left(c_{2}^{A}\right) \geqslant u\left(c_{1}^{H}\right)$

These equations state that when an informed depositor observes that the gambling asset has appeared, he has no incentives to withdraw in the low and high-liquidity regions, respectively. Eq. (11) states that the expected utility of a patient depositor in a lowliquidity bank is higher when he waits than when he withdraws at $t=1$. The equation is interpreted as follows: when the gambling asset succeeds in the low-liquidity bank (which happens with probability $\eta$ ), if in the other bank the gambling asset does not appear or appears and succeeds (which happens with probability $q$ ), the depositor receives $c_{2}^{L}$. However, when the gambling asset in the other region fails, then depositors receive the lower amount of $c_{2}^{c}$, as the low-liquidity bank is not able to retrieve its interbank deposit with the other bank. Similarly, when the gambling asset fails in the low-liquidity region (with probability $1-\eta$ ), if in the other bank the gambling asset does not appear or appears and succeeds, the bank can use the available funds from the interbank market to pay depositors, and so the depositor receives $c_{2}^{F}$, whereas if the gambling asset appears and fails the depositor just receives $c_{2}^{B}$ (which is zero, when there is no storage from $t=1$ to $t=2$ ). Eq. (12) has a similar interpretation. It represents the expected utility of a patient depositor in a high-liquidity bank. Recall that in this case, secondperiod consumption is just affected by what happens in this bank. When the gambling asset succeeds in the high-liquidity bank, (which happens with probability $\eta$ ) the depositor receives $c_{2}^{H}$, while when the gambling asset fails, the depositor just receives $c_{2}^{A}$ (which is zero if there is no storage).

In the discussion that follows, we assume that the value of $\eta$ is such that the above incentive constraints are never satisfied. Formally, the condition for depositors to run on the bank is summarized in Lemma 1.

Lemma 1. Let $\hat{\eta}$ be the level of $\eta$ for which the more restrictive of the two incentive constraints (11) and (12) is satisfied. Then, for $\eta<\hat{\eta}$, the incentive constraints are violated and there are runs.

We assume, that the value of $\eta$ is sufficiently low (below $\hat{\eta}$ ), so there are always runs. ${ }^{11}$ Let us describe the sequence of events at date $t=1$. First, banks observe the liquidity shock and withdraw interbank deposits when its region results to be in the high-liquidity demand one. Then, the appearance of the gambling asset is observed by informed depositors and finally, impatient and informed depositors withdraw their money from banks.

As the type of the consumer is private information, the bank cannot distinguish whether the withdrawal is due to liquidity issues or information induced ones. Additionally, agents arrive at the bank and are paid sequentially, therefore, this first-comefirst-served service plus the illiquidity of the long-term investment, makes the bank subject to runs whenever the proportion of withdrawals at $t=1$ is greater than $w^{s}(s=L, H)$.

\footnotetext{
${ }^{11}$ In this paper, we focus on essential bank runs, that is, bank runs that cannot be avoided, and hence the necessary and sufficient condition for a bank run is that the incentive constraint be violated. We then rule out pure-panic runs of the Diamond and Dybvig type. See Allen and Gale (2007) for a discussion of this issue.
}

Let the probability of being paid in state $s$, when the gambling asset appears, be $\rho_{s}=\frac{w^{s}}{\alpha\left(1-w^{s}\right)+w^{s}}$, where the numerator represents total supply and the denominator total demand. So with probability $\rho_{s}(s=L, H)$, type- 1 and informed type-2 depositors receive $c_{1}^{s}$, and with probability $\left(1-\rho_{s}\right)$ they will receive zero. ${ }^{12}$

The ex-ante expected utility when there is a run, $\widehat{U}(p)$, is as follows:

$$
\begin{aligned}
\widehat{U}= & \frac{1-p}{2}\left\{w^{H} u\left(c_{1}^{H}\right)+\left(1-w^{H}\right) u\left(c_{2}^{H}\right)+w^{L} u\left(c_{1}^{L}\right)\right. \\
& \left.+\left(1-w^{L}\right)\left[(1-p) u\left(c_{2}^{L}\right)+p u\left(c_{2}^{c}\right)\right]\right\}+\frac{p}{2}\left\{w^{H}\left[\rho_{H} u\left(c_{1}^{H}\right)+\left(1-\rho_{H}\right) u(0)\right]\right. \\
& +\left(1-w^{H}\right)\left\{\alpha \rho_{H} u\left(c_{1}^{H}\right)+\left[\alpha\left(1-\rho_{H}\right)+(1-\alpha)\right] u(0)\right\} \\
& +w^{L}\left[\rho_{L} u\left(c_{1}^{L}\right)+\left(1-\rho_{L}\right) u(0)\right]+\left(1-w^{L}\right)\left\{\alpha \rho_{L} u\left(c_{1}^{L}\right)\right. \\
& \left.\left.+\left[\alpha\left(1-\rho_{L}\right)+(1-\alpha)\right] u(0)\right\}\right\}
\end{aligned}
$$

Let us consider the case of a depositor in region A, that is symmetrical to that of a depositor in region $B$. If the gambling asset does not appear and region $\mathrm{A}$ faces a high-liquidity shock, consumption in both periods is as promised $\left(c_{t}^{H}, t=1,2\right)$. This explains the first row of the objective function. However, when region $A$ faces a low-liquidity shock and in region $\mathrm{B}$ there was a bank run at $t=1$ (which occurs with probability $p$ ), the bank in region A will be affected by contagion at $t=2$ since it cannot retrieve its interbank deposits, and so patient depositors receive the lower amount $c_{2}^{c}$. This gives the second row of the objective function. The other rows present the case where the gambling asset appears in region $A$ (the one we are considering as home) and so the bank in region $A$ is affected by a bank run. As mentioned above, in this case, with probability $\rho_{s}$ type- 1 and informed type- 2 receive $c_{1}^{s}$ and with probability $\left(1-\rho_{S}\right)$ they receive zero.

Let us call $\Psi_{R U N S}=\left(c_{t R}^{s}, c_{2 R}^{A}, c_{2 R}^{c}, c_{2 R}^{F}, c_{2 R}^{B}, x_{R}, y_{R}, k_{R}, d_{t R}^{s}\right)$ the allocation with bank runs, and $\widehat{U}$ the expected utility achieved.

The complete characterization of the optimal problem is provided in Appendix B. The optimal consumption levels are obtained maximizing the ex-ante expected utility with runs, subject to the resource and the banker's incentive compatibility constraints.

\subsection{Moral hazard with information: the run-proof contract}

We now consider a contract which ensures bank runs will not occur, as a result of the negative information shock. This contract solves the same problem as the one in subsection 4.2 with two additional incentive constraints given by Eqs. (11) and (12). We call the result to the bank's optimization problem, when bank runs are avoided, the run-proof contract.

This run-proof contract guarantees that the incentive compatibility constraints are always satisfied. Essentially, what the contract does is to reduce first-period consumption so there are no runs.

Note that this contract allows bankers to gamble with depositors' funds and maintain their investments until $t=2$. However, as it is shown later, the run-proof contract might not be optimal. In some cases, it is welfare improving to allow bank runs. This comparison is missing in BC paper. In their case, with no information, there are never runs, and the banks would always gamble and maintain their investment until $t=2$ (for a sufficiently low $p$ ).

Let us call $\Psi_{R P}=\left(c_{t R P}^{s}, c_{2 R P}^{A}, c_{2 R P}^{c}, c_{2 R P}^{F}, c_{2 R P}^{B}, x_{R P}, y_{R P}, k_{R P}, d_{t R P}^{s}\right)$ the allocation when banks offer the run-proof contract and $\widetilde{U}(p, \eta)$ the expected utility achieved.

This contract is presented in Appendix C.

\footnotetext{
12 Recall that the long-term investment is illiquid, or equivalently, that its liquidation value is close to zero.
} 


\subsection{Comparative statics}

A comparison between the allocation that allows for runs, and the run-proof contract is summarized in the proposition below. For a similar type of analysis, in a single-bank economy without moral hazard, see Alonso (1996).

Proposition 3. Let $\eta^{*}<\hat{\eta}$ be the level of $\eta$, for which the expected utility with both contracts, the run-proof contract and the one that allows for runs is equalized, that is, $\widehat{U}=\widetilde{U}$. For values of $\eta<\eta^{*}$ and a sufficiently low $p$, the allocation that allows for runs at $t=1$ (and hence punishes banks by forcing liquidation and not allowing banks to operate until $t=2$ ) is preferred to the run-proof contract. For $\eta^{*}<\eta \leqslant \hat{\eta}$, the run-proof contract is preferred.

Proof. The idea of the proof is to analyze the values that both functions take at the extreme points $\eta=0$ and $\eta=\hat{\eta}$, in order to see whether both functions intersect.

First, we demonstrate that for any $p>0$ (but small), when $\eta=0$, the expected utility with bank runs is higher than in the run-proof case. In order to show this, note that when $p \rightarrow 0$, the optimal contract with bank runs (Appendix $B$ ) becomes identical to the problem defined in Appendix A (moral hazard without information). From Proposition 2, we know that this latter contract achieves the first best, and hence the optimal contract with bank runs would also be optimal. On the other side, the run-proof contract will not achieve the first best when $p \rightarrow 0$, as it considers the two additional incentive constraints (11) and (12) (which affect consumption even in the absence of appearance of the gambling asset). Hence, this demonstrates that for a sufficiently low $p$ the expected utility with bank runs should be higher, at the extreme point $\eta=0$.

Second, when $\eta=\hat{\eta}$, then we know from Lemma 1 that there are no runs, that is, the incentive compatibility constraints are automatically satisfied. Therefore, at this point, individuals would be strictly worse off by running on the bank, and so the contract with bank runs would be dominated. ${ }^{13}$ In fact, the only relevant contract is the run-proof one.

Finally, we show that the expected utility with bank runs is independent of $\eta,{ }^{14}$ while the expected utility in the run-proof case is increasing in $\eta$. This can be seen by comparing Eq. (13) (the expected utility with bank runs) with Eq. (15), expected utility in the run-proof case. Then, as the expected utility with runs is independent of $\eta$, while the expected utility in the run-proof case is increasing in $\eta^{15}$ this demonstrates that the functions should intersect at some point $\eta<\hat{\eta}$, that is, there exists a threshold value of $\eta, \eta^{*}<\hat{\eta}$, for which the two utility functions are equalized.

Consequently, for values of $\eta \geqslant \eta^{*}$, banks are allowed to gamble and maintain the investment until $t=2$ (as in BC). Our paper shows that when information is introduced and the gambling asset is risky $(\eta<\hat{\eta})$, the incentive constraints should be taken into account. In fact, for certain parameter values, it is welfare improving to run on banks $\left(\eta<\eta^{*}\right)$.

Finally, there are differences in the channel of contagion in the two scenarios. When bank runs are allowed contagion is due to the

\footnotetext{
${ }^{13}$ Note that the optimal contract with bank runs, penalizes some of the type- 1 agents that arrive late to the bank.

${ }_{14}$ Bank runs occur at $t=1$ for every $\eta<\hat{\eta}$, and so the expected utility with bank runs just depends on the probability of appearance of the gambling asset $p$.

15 Note that in Eq. (15), $q=1-p+p \eta$. Focusing on the maximization problem defined in Appendix C (run-proof contract), it can be seen that as $\eta$ increases, the incentive compatibility constraints (11) and (12) become less restrictive, and consequently the expected utility with the run-proof contract increases. Moreover, as $\eta$ increases aggregate uncertainty decreases, the expected return increases and so the expected utility also increases.
}

interaction of bad investments and information while in the runproof contract it is just a cascade effect (as in BC).

\section{Welfare comparisons: numerical examples}

In order to explore the relevance of Propositions 2 and 3, some numerical simulations are carried out.

The following utility function is assumed:

$U^{i}\left(c_{i}\right)=\frac{\left(g+c_{i}\right)^{1-\delta}}{1-\delta} \quad \delta>1, k>0$

$i=1,2$

where $g$ is a positive constant and $\delta$ the relative risk aversion coefficient. $^{16}$

Fig. 2 simulates Proposition 2, derived in $\mathrm{BC}{ }^{17}$ The figure displays the expected utility with moral hazard, and the expected utility achieved when moral hazard is prevented by restricting long-term investment. It can be seen that the critical probability of success of the gambling asset above which moral hazard should be restrained is approximately 0.30 . Additionally, in all simulations, we have consistently checked for this critical probability, in order to ensure that for the assumed value of $p$ the simulations are relevant.

Fig. 3 simulates Proposition 3. The figure represents the expected utility achieved both when bank runs are allowed and in the run-proof contract, as a function of the probability of success of the gambling asset. The figure displays the critical $\eta^{*}$, for which both utilities are equalized. It can be seen that $\eta^{*}=0.73$. Then, for values of $\eta<\eta^{*}$ it is welfare improving to run on banks. On the contrary, when $\eta>\eta^{*}$, the best contract is one that prevents bank runs. ${ }^{18}$ The logic behind gambling for values of $\eta>0.73$ is that the probability of the bad state (default) is quite small (so $\eta$ high). In other words, in these cases, the asset is not very risky, and so it welfare improving to maintain the investment, or equivalently, to gamble.

Figs. 4-6 carry out comparative statics. The idea is to determine the variation of the critical probability of success of the gambling asset, $\eta^{*}$, as a function of the model parameters. In Fig. 4, all parameters remain constant, except for the relative risk-aversion coefficient, which has increased to $\delta=4.0$. By comparing Figs. 3 and 4, it can be seen that the critical probability is increasing in risk aver$\operatorname{sion}\left(\eta^{*}=0.87\right)$. Then, as individuals become more risk averse, they are more reluctant to allow the bank to gamble and maintain their investment (the run-proof contract), and so the contract that allows for runs is preferred for a larger set of parameters. Similarly, Fig. 5 carries out the same comparison for a higher value of the return, $R=1.8$. Again, comparing Figs. 3 and 5 , it can be seen that the critical probability is decreasing in the return $\left(\eta^{*}=0.69\right)$. This is because when the long-term asset is more productive depositors are more willing to continue the investment, and so the run-proof contract is preferred for a larger set of parameters. Finally, Fig. 6 shows the expected utility with both contracts when the average proportion of impatient consumers decreases to $\gamma=0.4$. It can be also observed that the critical probability increases $\left(\eta^{*}=0.75\right)$, which reflects the fact that bank run allocation penalizes type- 1 consumers relatively more than type- 2 consumers, as with bank runs some type- 1 consumers are rationed at $t=1$. Therefore, when the average proportion of type- 1 consumers decreases, the bank-run contract is preferred for a larger set of parameters.

\footnotetext{
16 The positive constant $g$ keeps the objective function bounded for all weakly positive consumption levels.

17 The optimization problems have been programmed and solved with GAMS.

18 Note that all figures have been simulated up to the point where $\eta=\hat{\eta}$. In fact, at this point, the expected utility with bank runs is not defined.
} 


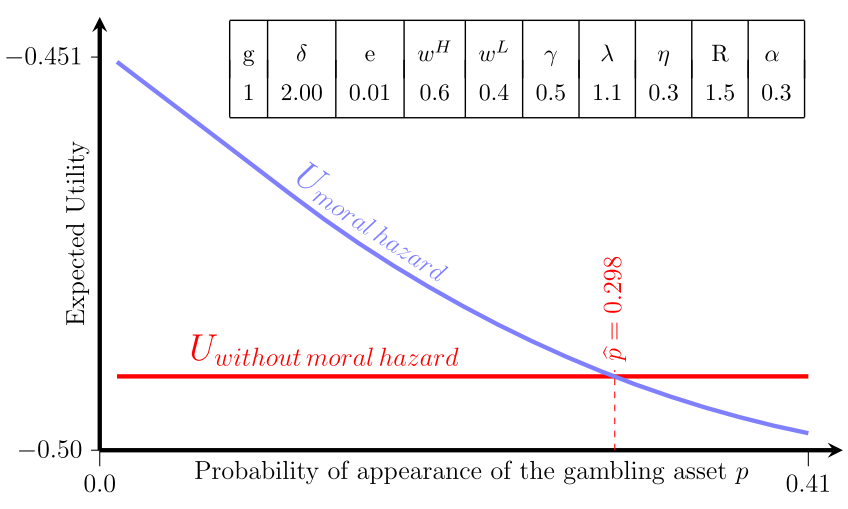

Fig. 2. Expected utility with moral hazard and without moral hazard as a function of the probability of appearance of the gambling asset $p$ (Proposition 2 ).

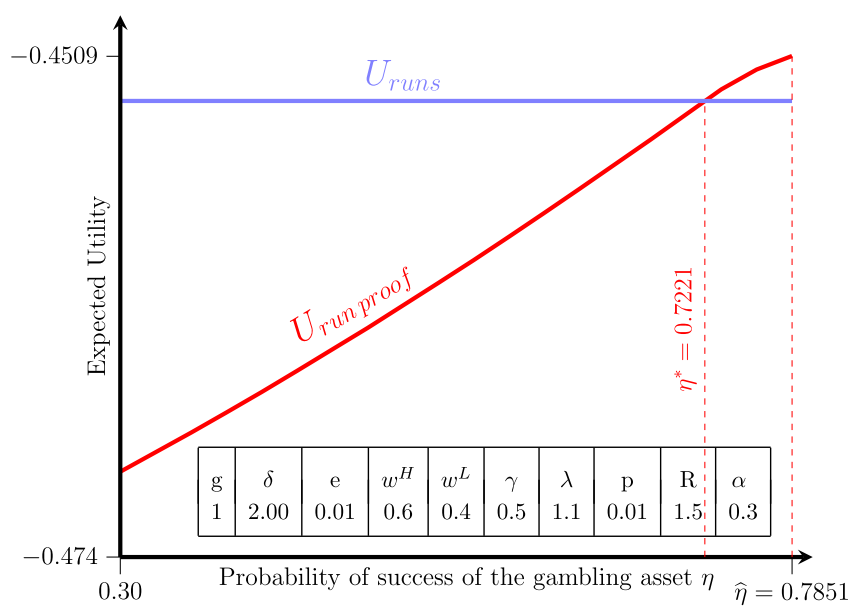

Fig. 3. Expected utility achieved with runs and without runs as a function of the probability of success of the gambling asset $\eta$ (Proposition 3 ).

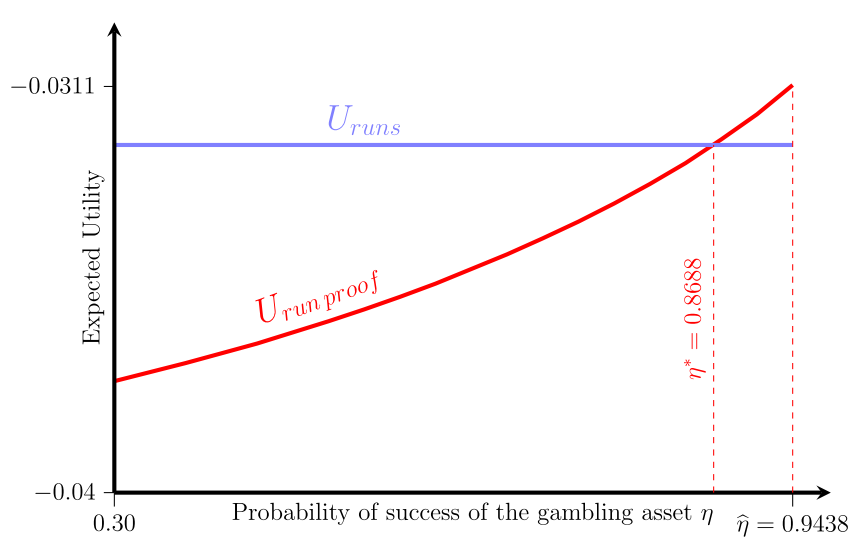

Fig. 4. Expected utility achieved with runs and without runs as a function of the probability of success of the gambling asset, and higher risk aversion $(\delta=4.00)$.

Overall, the numerical simulations show that banks are allowed to gamble and maintain the investment, when the gambling asset is relatively safe. We see that the critical probability is increasing in the level of risk aversion and it is decreasing in the long-term return and in the proportion of type- 1 consumers.

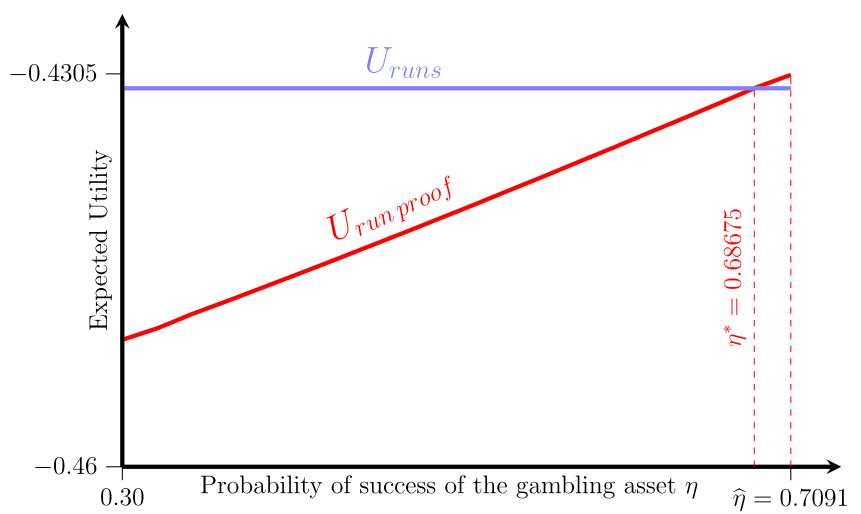

Fig. 5. Expected utility achieved with runs and without runs as a function of the probability of success of the gambling asset and higher return $(R=1.8)$.

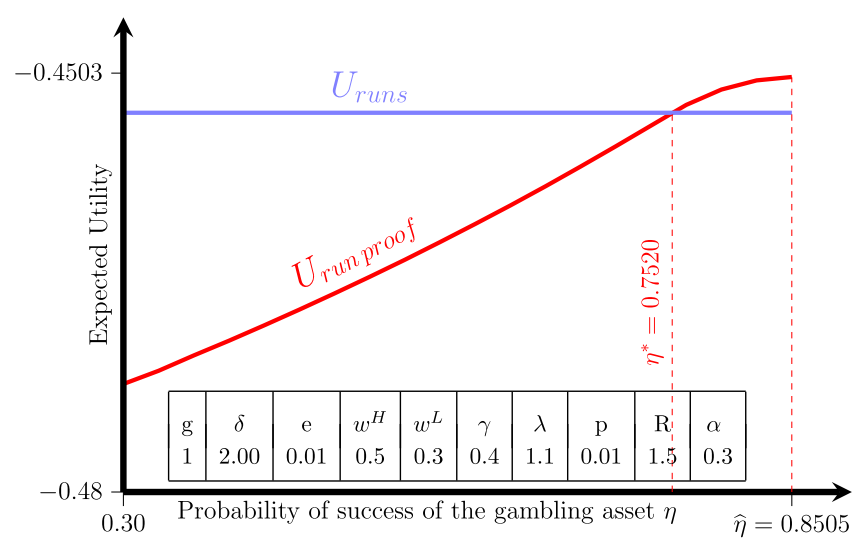

Fig. 6. Expected utility achieved with runs and without runs as a function of the probability of success of the gambling asset and lower average proportion of impatient consumers $(\gamma=0.4)$.

\section{Concluding remarks}

This paper analyzes market discipline in a many-bank economy where contagion and bank runs interact. In particular, we build on the model by Brusco and Castiglionesi (BC), but we modify their framework by introducing the possibility of differently-informed depositors. In BC framework, moral hazard arises due to the existence of undercapitalized banks and no informed depositors. They show that for certain parameter values, depositors prefer a contract that allows banks to gamble with their money to one that restricts banks to be sufficiently capitalized, in order to avoid the moral hazard problem.

We show that if depositors have incentives to acquire information, negative information induces depositors to run on banks. Therefore, in order to avoid runs (and allow banks to gamble and maintain the investment) two additional constraints need to be imposed in the bank maximization problem. We refer to this contract as the run-proof contract. We then derive the threshold probability of success of the gambling asset, $\eta^{*}$, for which two contracts, the run-proof contract and the contract that allows for runs, deliver the same expected utility. For probabilities below the threshold value $\left(\eta<\eta^{*}\right)$ it is welfare improving to run on banks. Overall, depositors will only allow banks to gamble with their money, when the probability of success of the gambling asset is sufficiently high (the asset is not very risky).

Both when banks are allowed to gamble and maintain the investment or when there is a run, the contagion effect remains small. This result is very important as it is precisely during crises, 
when governments tend to adopt blanket guarantees to avoid runs (in fear of a systemic crisis) and thus weaken market discipline. Our results suggest that, in certain circumstances, allowing for runs (and hence contagion) might be welfare superior to maintaining risky banks operating. Finally, there are differences in the channel of contagion, in the two scenarios. When bank runs are allowed contagion is due to the interaction of bad investments and information while in the run-proof contract it is just a cascade effect.

The results of our paper emphasize the importance of information and private monitoring in promoting market discipline.

\section{Acknowledgements}

The authors would like to thank an anonymous referee, Ike Mathur (the editor), Sandro Brusco and seminar participants at the NFA 2011, Universidad Carlos III, XVI World Congress of the International Economic Association and MFA 2010 for their helpful comment in an earlier version of this paper. This research is partially funded by the Spanish Ministry of Science and Innovation, Project, ECO2010-17158.

\section{Appendix A}

The problem to be solved, in the absence of information and when capital is scarce, is the following one ${ }^{19}$ :

$$
\begin{aligned}
\max _{x, y, k,\left\{c_{t}^{s}, d_{t}^{s}\right\}_{t=1,2}^{s=L,}} \widetilde{U}= & \frac{1}{2}\left\{w^{H} u\left(c_{1}^{H}\right)+\left(1-w^{H}\right)\left[q u\left(c_{2}^{H}\right)+(1-q) u\left(c_{2}^{A}\right)\right]\right\} \\
& +\frac{1}{2}\left\{w^{L} u\left(c_{1}^{L}\right)+\left(1-w^{L}\right) q\left[q u\left(c_{2}^{L}\right)+(1-q) u\left(c_{2}^{c}\right)\right]\right\} \\
& +\frac{1}{2}\left(1-w^{L}\right)(1-q)\left[q u\left(c_{2}^{F}\right)+(1-q) u\left(c_{2}^{B}\right)\right]
\end{aligned}
$$

subject to

$$
\begin{aligned}
& \xi x \geqslant e, \\
& w^{H} c_{1}^{H}+d_{1}^{H} \leqslant y+k_{i} c_{1}^{L} \\
& \left(1-w^{H}\right) c_{2}^{A} \leqslant\left(y+k_{i} c_{1}^{L}-w^{H} c_{1}^{H}-d_{1}^{H}\right)-k_{j} c_{2}^{A} \\
& \left(1-w^{H}\right) c_{2}^{H}+d_{2}^{H} \leqslant R x+\left(y+k_{i} c_{1}^{L}-w^{H} c_{1}^{H}-d_{1}^{H}\right)-k_{j} c_{2}^{H} \\
& w^{L} c_{1}^{L}+d_{1}^{L} \leqslant y-k_{j} c_{1}^{L} \\
& \left(1-w^{L}\right) c_{2}^{L}+d_{2}^{L} \leqslant R x+\left(y-k_{j} c_{1}^{L}-w^{L} c_{1}^{L}-d_{1}^{L}\right)+k_{i} c_{2}^{H} \\
& \left(1-w^{L}\right) c_{2}^{c} \leqslant R x+\left(y-k_{j} c_{1}^{L}-w^{L} c_{1}^{L}-d_{1}^{L}\right)+k_{i} c_{2}^{A} \\
& \left(1-w^{L}\right) c_{2}^{F} \leqslant\left(y-k_{j} c_{1}^{L}-w^{L} c_{1}^{L}-d_{1}^{L}\right)+k_{i} c_{2}^{H} \\
& \left(1-w^{L}\right) c_{2}^{B} \leqslant\left(y-k_{j} c_{1}^{L}-w^{L} c_{1}^{L}-d_{1}^{L}\right)+k_{i} c_{2}^{A} \\
& \left.11 d_{1}^{H}+q d_{2}^{H}\right)+\frac{1}{2}\left(d_{1}^{L}+q^{2} d_{2}^{L}\right)+p(\lambda-1) R x \geqslant e R \\
& \overline{2}\left(c_{2}^{c} \geqslant 0, \quad c_{2}^{F} \geqslant 0, \quad c_{2}^{B} \geqslant 0\right. \\
& k \geqslant 0, \quad c_{2}^{A} \geqslant 0, \quad c_{2}^{c} \geqslant 0, \quad c_{t}^{S} \geqslant 0, \text { where } s=L, H \text { and } t=1,2 \\
& d_{t}^{S} \geqslant 0, \quad y \geqslant 0, \\
& y+x-k_{i}+k_{j} \leqslant 1+e, \quad x \geqslant 0, \quad y \geqslant 0
\end{aligned}
$$

where $k_{i}$ represents interbank deposits given to the other bank and $k_{j}$ interbank deposits received from the other bank, (with $k_{i}=k_{j}=k$ ), $c_{t}^{s}$ is the consumption offered to a type $t$ consumer (with $t=1,2$ ) in state $s$ (with $s=L, H$ ). We define as $c_{2}^{A}$ the consumption of a patient depositor in a high-liquidity region, when its own investment fails and so all the available funds are those from storage (if any), $c_{2}^{c}$ is

\footnotetext{
19 This is a revised version of the original problem solved by Brusco and Castiglionesi (2007, pp. 2299-2300).
}

the consumption of a patient depositor in the low-liquidity region when its long-term investment is successful and the bank in the other region (say B) fails. In this case, bank A cannot retrieve completely the interbank deposit, and so there is contagion from region $\mathrm{B}$ to region $\mathrm{A}, c_{2}^{F}$ is the consumption of a patient depositor in the low-liquidity region when its own investment fails, but that of the other region does not. In this case, the available funds to pay depositors are those obtained from the interbank market and from storage (if any). When both regions' investments fail, which happens with probability $(1-q)^{2}$, then there is a meltdown of the entire financial system, and depositors receive $c_{2}^{B}$. Finally, $d_{t}^{s}$ are dividends received by the capitalist at $t=1,2$ in state $s$ (with $S=L, H)$.

The interpretation of this problem is as follows ${ }^{20}$ : Eq. (15) is the expected utility to be maximized. The first row of the optimization program is the expected utility of a depositor when the region has the high-liquidity shock at $t=1$. Note that in this case second-period consumption is not affected by what happens in the other region. The second and third rows represent the expected utility of a depositor when the region is affected by a low-liquidity shock at $t=1$. In this case, second-period consumption is affected by what happens in the other region.

Eq. (16) states that the bank is insufficiently capitalized, and so it has incentives to invest in the gambling asset. Eq. (17) is the firstperiod constraint in a high-liquidity region while Eqs. (18) and (19) are the second-period constraints in this high-liquidity region. Eq. (20) is the first-period constraint in a low-liquidity region while Eqs. (21)-(24) are second-period constraints for a low-liquidity region, depending on what has happened in the other region.

Eq. (25) is the participation constraint for investors. It is explained as follows: with probability $1 / 2$ the bank will have a high-liquidity shock, and the capitalist receives the second-period dividend if the gambling asset does not appear or it appears and succeeds (which occurs with probability $q$ ). With probability $1 / 2$ the bank will have a low-liquidity shock, and in this case the capitalist receives the second-period dividend if in both regions either the gambling assets do not appear or they appear and succeed (which happens with probability $q^{2}$ ). Finally, when the gambling asset appears the capitalist retains the amount $(\lambda-1) R x$. Eqs. (26) and (27) present the nonnegativity constraints. Finally, the budget constraint at $t=0$ is given by Eq. (28).

\section{Appendix B. Optimal contract with bank runs}

The optimal consumption levels are obtained maximizing the ex-ante expected utility with runs, subject to the resource and incentive compatibility constraints, (16)-(28). The problem to be solved, when bank runs are allowed is as follows:

$$
\begin{aligned}
\max _{x, y, k,\left\{c_{t}^{s}, d_{t}^{s}\right\}_{t=1,2}^{S=L, H}} \widehat{U}= & \frac{1-p}{2}\left\{w^{H} u\left(c_{1}^{H}\right)+\left(1-w^{H}\right) u\left(c_{2}^{H}\right)+w^{L} u\left(c_{1}^{L}\right)\right. \\
& \left.+\left(1-w^{L}\right)\left[(1-p) u\left(c_{2}^{L}\right)+p u\left(c_{2}^{c}\right)\right]\right\} \\
& +\frac{p}{2}\left\{w^{H}\left[\rho_{H} u\left(c_{1}^{H}\right)+\left(1-\rho_{H}\right) u(0)\right]\right. \\
& +\left(1-w^{H}\right)\left\{\alpha \rho_{H} u\left(c_{1}^{H}\right)+\left[\alpha\left(1-\rho_{H}\right)+(1-\alpha)\right] u(0)\right\} \\
& +w^{L}\left[\rho_{L} u\left(c_{1}^{L}\right)+\left(1-\rho_{L}\right) u(0)\right]+\left(1-w^{L}\right)\left\{\alpha \rho_{L} u\left(c_{1}^{L}\right)\right. \\
& \left.\left.+\left[\alpha\left(1-\rho_{L}\right)+(1-\alpha)\right] u(0)\right\}\right\}
\end{aligned}
$$

subject to

(16)-(28).

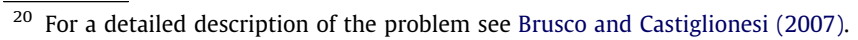




\section{Appendix C. The run-proof Contract}

The problem to be solved, when banks offer the run-proof contract is identical to that of Appendix B, with two additional incentive compatibility constraints, that is:

Max. (15).

subject to.

(16)-(28)

and

$\eta\left[q u\left(c_{2}^{L}\right)+(1-q) u\left(c_{2}^{c}\right)\right]+(1-\eta)\left[q u\left(c_{2}^{F}\right)+(1-q) u\left(c_{2}^{B}\right)\right] \geqslant u\left(c_{1}^{L}\right)$

$\eta u\left(c_{2}^{H}\right)+(1-\eta) u\left(c_{2}^{A}\right) \geqslant u\left(c_{1}^{H}\right)$

All the optimization problems have been programmed and solved with GAMS.

\section{References}

Allen, F., Babus, A., 2008, Networks in Finance, Wharton Financial Institutions Center, Working Paper 08-07.

Allen, F., Gale, D., 2000. Financial contagion. Journal of Political Economy 108, 1-33. Allen, F., Gale, D., 2007. Understanding Financial Crises. Oxford University Press.

Alonso, I., 1996. On avoiding bank runs. Journal of Monetary Economics 37, 73-87.

Barth, J.R., Caprio, G., Levine, R., 2004. Bank Regulation and supervision: what works best? Journal of Financial Intermediation 13 (2), 205-242.

Bhattacharya, S., Boot, W.A., Thakor, A.V., 1998. The economics of bank regulation. Journal of Money, Credit and Banking 30 (4), 745-770.

Brusco, S., Castiglionesi, F., 2007. Liquidity coinsurance, moral hazard and financial contagion. Journal of Finance 62 (5), 2275-2302.

Calomiris, Charles W., Kahn, C., 1991. The role of demandable debt in structuring optimal banking arrangements. American Economic Review 81 (June), 497-513.

Castiglionesi, F., 2007. Financial contagion and the role of the central bank. Journal of Banking and Finance 31 (1), 81-101.

Chen, Y., Hasan, I., 2006. The transparency of the banking system and the efficiency of information bank runs. Journal of Financial Intermediation 15 (3), 307-331.
Cubillas, E., Fonseca, A., Gonzalez, F., 2012. press. Banking crises and market discipline: international evidence. Journal of Banking and Finance 36 (8), 22852298.

Demirgüç-Kunt, A., Huizinga, H., 2004. Market discipline and deposit insurance. Journal of Monetary Economics 51, 375-399.

Diamond, D.W., Rajan, R., 2001a. Liquidity risk, liquidity creation and financial fragility: a theory of banking. Journal of Political Economy 109 (April), 287-327.

Diamond, D.W., Rajan, R., 2001b. Banks and liquidity. American Economic Review 91 (May), 422-425.

Diamond, D.W., Rajan, R., 2005. Liquidity shortages and banking crises. Journal of Finance 60 (2), 615-647.

Diamond, D.W., Rajan, R., 2006. Money in a theory of banking. American Economic Review 96 (1), 30-53.

Dwyer, G., Samartín, M., 2009. Why do banks promise to pay par on demand? Journal of Financial Stability 5 (June), 147-169.

European Central Bank, 2010. Financial Networks and Financial Stability. Special Issue in the Financial Stability Review June 2010.

Flannery, M., 1994. Debt maturity and the deadweight cost of leverage: optimally financing banking firms. American Economic Review 84 (March), 320-331.

Fonseca, A.R., González, F., 2010. How bank capital vary across countries: the influence of cost of deposits, market power and bank regulation. Journal of Banking and Finance 34, 892-902.

Gorton, G., Huang, L., 2003. Banking panics and the origin of central banking. In: David, E.Altig., Bruce, D.Smith. (Eds.), Evolution and Procedures in Central Banking. Cambridge University Press, Cambridge, pp. 181-219.

Hadad, M.D. Agusman, A. Monroe, G.S., Gasbarro, D., Zumwalt, J.K., 2011. Market discipline, financial crisis and regulatory changes: evidence from Indonesian banks. Journal of Banking and Finance 35, 1552-1562.

Hasman, A., Samartín, M., 2008. Information acquisition and financial contagion. Journal of Banking and Finance 32, 2136-2147.

Hosono, K., Iwaki, H., Tsuru, K., 2005. Banking Crises, Deposit Insurance, and Market Discipline: Lessons from the Asian Crises, RIETI Discussion Paper Series 05-E029.

Jacklin, C., Bhattacharya, S., 1988. Distinguishing panics and information based bank runs: welfare and policy implications. Journal of Political Economy 96, 568-592.

Jean-Baptiste, E., 1999. Demand Deposits as an Incentive Mechanism. Unpublished Paper, Wharton School, University of Pennsylvania.

Martinez Peria, M.S., Schmukler, S.L., 2001. textquotedblleft Do depositors punish banks for bad behavior? Journal of Finance 56, 1029-1051.

Qi, J., 1998. Bank liquidity and stability in an overlapping generations model. Review of Financial Studies 7 (2), 389-417.

Samartín, M., 2003. Should bank runs be prevented? Journal of Banking and Finance 27 (5), 977-1000. 